\title{
PERSPECTIVE
}

\section{Partnering with Psychiatry to Close the Education Gap: An Approach to the Addiction Epidemic}

\author{
Jeanette M. Tetrault, M.D. ${ }^{7}$ and Ismene L. Petrakis, M.D. ${ }^{2,3}$ \\ 'Department of Internal Medicine, Yale University School of Medicine, New Haven, CT, USA; ${ }^{2}$ Department of Psychiatry, Yale University School of \\ Medicine, New Haven, CT, USA; ${ }^{3}$ VA Connecticut Healthcare System, West Haven, CT, USA.
}

Addiction has reached epidemic proportions in the U.S., yet the workforce prepared to care for this population is woefully inadequate. Of the 23 million Americans suffering from addiction, only $11 \%$ receive treatment, creating a substantial treatment gap. There have been calls to improve addiction education at all levels of training in order to prepare medical providers with the skills to identify patients with substance use, briefly treat if indicated, and/or refer more complex cases to specialty care. These calls have been put forth to address the education gap, wherein physicians in training are exposed to numerous patients who are suffering from addiction but have few curricular hours dedicated to the identification and management of this population. We propose that strategic partnerships between psychiatry and internal medicine can address the education gap that exists with regard to addiction, ultimately addressing the treatment gap which is plaguing this country.

KEY WORDS: substance-related disorders; medical education. $\mathrm{J}$ Gen Intern Med 32(12):1387-9

DOI: $10.1007 /$ s11606-017-4140-9

(C) Society of General Internal Medicine (outside the USA) 2017

$\mathrm{W}$ ith surging rates of overdose death, now surpassing motor vehicle accidents as the leading cause of injury-related death in this country, the opioid epidemic in the U.S. has prompted a great deal of soul-searching, leading to action among lawmakers at many levels up to the U.S. federal government, and has included a rare bipartisan effort in Congress to address this problem. ${ }^{1}$ The Comprehensive Addiction and Recovery Act (CARA), signed into law in July 2016, expands treatment access to patients in need. Additionally, the U.S. Surgeon General issued a report in November 2016 with a call to action to reduce stigma and raise awareness of the impact of addiction in this country., ${ }^{2,3}$ These efforts may be threatened if significant changes are made to the Affordable Care Act (ACA) by the current administration, as Medicaid expansion has improved treatment access, and the ACA considers treatment for substance use disorders an essential health benefit. ${ }^{4}$ Therefore, access to addiction

Received December 23, 2016

Revised April 19, 2017

Accepted July 12, 2017

Published online August 1, 2017 treatment will likely be affected with changes to health care legislation. It is important to note that the current administration has established a bipartisan commission to address the opioid epidemic.

Along with the federal government's recent emphasis on access to opioid treatment, one initiative proposed by the White House Office of National Drug Control and Policy (ONDCP) was to request, in March 2016, that medical schools sign a pledge that stated, "Beginning Fall of 2016, we will require all students to take some form of prescriber education in line with CDC [G]uidelines [for Prescribing Opioids for Chronic Pain] in order to graduate." While 61 out of 170 medical schools nationwide signed the pledge, others, including our institution at Yale University School of Medicine, found that signing the pledge alone was woefully inadequate in addressing what is one of the main barriers to providing comprehensive and adequate treatment: the lack of quality teaching in evidence-based approaches to the identification, prevention, and treatment of addiction. The inadequate focus on addiction education has even prompted students themselves from several medical schools to seek outside training in lifesaving measures to deal with opioid overdose and to request improved curriculum in order to better prepare them to become physicians in the face of the current crisis. ${ }^{5}$

Although the recent attention to the opioid epidemic presents a unique opportunity to advocate for action, it is important to recognize that the opioid crisis is only part of a larger public health threat, namely addiction. It is clear that overdose deaths contribute substantially to mortality. Additionally, recent Centers for Disease Control and Prevention (CDC) data suggest that there is a marked increase in death among white middle-aged men due to drug and alcohol poisoning, suicide, and chronic liver disease related to alcohol and other drug use. ${ }^{6}$ Despite the large burden of disease and its public health impact, addiction continues to be one of the most stigmatized - and from a layman's perspective, poorly understood — chronic diseases in this country. ${ }^{7-9}$ Addiction is not only stigmatized among the general population; even within the hallowed halls of medical training, a "hidden curriculum" exists whereby some seasoned clinicians pass on the sentiment that addiction is a moral failing on the part of the patient and the assumption that addiction cannot be adequately treated. ${ }^{10,11}$ This has created a situation where individuals who suffer from addiction may not recognize their own symptoms or may minimize them and find it difficult 
to access quality treatment, especially treatment that is appropriately planned and not fraught with pejorative consequences. Further, both patients and physicians may experience the relapsing/remitting natural history of the disease as a "treatment failure," further perpetuating the stereotypes.

In addition to stigma, there are important factors contributing to a widely recognized treatment gap, whereby only $11 \%$ of the 22 million Americans suffering from addiction actually receive specialized treatment. ${ }^{12}$ These factors include poor reimbursement structures to remunerate physicians who practice this work (despite major advances with Mental Health Parity and Addiction Equity Act of 2008) and a lack of quality-trained providers entering the workforce. ${ }^{13}$ Additionally, of the 19 million people with a substance use disorder not receiving treatment, upwards of $96 \%$ do not perceive a need for treatment, possibly influenced by a lack of provider education in the identification and assessment of the disorder in this population of non-treatment-seeking individuals. ${ }^{12}$ Calls for improved physician education in this area have been put forth and have slowly resulted in positive change. ${ }^{14}$ Many training programs are devoting more curricular time to addressing addiction at all levels of medical training, and several national organizations - including the American Academy of Addiction Psychiatry and the American Society of Addiction Medicine - have expanded their efforts to provide practicing physicians more training in addiction. Additionally, there are now two pathways to becoming board-certified as an addiction specialist, either through addiction psychiatry or, more recently, through addiction medicine, both with established fellowship training programs nationwide. ${ }^{13}$ There are 45 Accreditation Council for Graduate Medical Education (ACGME)accredited addiction psychiatry fellowship training programs in the U.S., and since 2011, the American Board of Addiction Medicine has accredited 47 addiction medicine fellowship training programs.

Despite these advances in educational opportunities in addiction psychiatry and addiction medicine, an education gap exists between the clinical settings in all specialties of medicine in which there are significant numbers of patients suffering from addiction, and the amount of curricular time devoted to training in addiction across the training spectrum. ${ }^{5,15}$ Several recent reviews and expert panels have suggested that the number of curricular hours devoted to training in addiction is a mere fraction of the time devoted to other chronic diseases often encountered in general psychiatry and general medicine. ${ }^{15-17}$ Additionally, the traditional structure for medical education has created silos of curricular content among academic departments, which makes both inter-departmental and interprofessional collaboration extremely challenging.

At our institution, we are committed to the concept that strategic partnering between psychiatry and medicine to address the education gap in addiction training at all levels of medical education - from medical students, to residents, to fellows, to faculty and physicians in practice- will improve knowledge and skills among trainees and attendings.
Additionally, with strategic partnerships working to reduce the stigma associated with this life-threatening disease, we will be able to develop a workforce of quality-trained providers who will close the treatment gap for the numerous patients who are in desperate need of help. This includes not only training addiction specialists, but perhaps more importantly, arming providers who practice in general medical settings with the tools necessary to identify, prevent, and treat addiction.

We believe that it is crucial to start early in medical school training, as attitudes and interests are influenced by early educational experiences. In response to the March 2016 ONDCP call to sign the pledge, we have developed a committee co-led by two physicians, one trained in addiction psychiatry and the other in addiction medicine, to create an addiction-focused curriculum thread with measurable goals and objectives that spans the 4 years of undergraduate medical school training. This curricular thread will complement an already established thread focused on comprehensive pain assessment and treatment and safe opioid prescribing. Additionally, we continue to partner to deliver case-based and evidence-based addiction-focused content to house-staff training in several disciplines at our institution. Lastly, being an institution that offers fellowship training in both addiction psychiatry and addiction medicine, we have found that sharing both didactic and experiential training for our advanced trainees not only strengthens the quality of the training experience but also improves trainee satisfaction, and may ultimately improve patient care.

We recognize the complementary nature that psychiatry and medicine bring to both treatment and education in addiction medicine. There are multiple comorbidities often associated with addiction, including serious mental illness, posttraumatic stress disorder, chronic infectious diseases including $\mathrm{HIV}$ and hepatitis $\mathrm{C}$, and chronic liver disease. By partnering to enhance educational content offered throughout the training spectrum, from students through physicians in training, we not only drive home its importance and focus on treatment of comorbid conditions, but we also avoid curricular redundancy and replace it with strategic repetition for skill development. Understandably, these partnerships require time and support. Sometimes the most successful and lasting partnerships are born of a coordinated response to a local or regional need. This may come in the form of a clinical, educational, research, or legislative call to action. When considering partnerships for an educational need, the inclusion of the curriculum committee or graduate medical education committee is essential, as is garnering departmental support.

The risk of any curricular restructuring proposal is the suggestion that other important educational content needs to be supplanted. At our institution, we have sought to minimize this within the medical school training by first examining the content of the existing curriculum and streamlining existing content, removing outdated material, making recommendations on language to avoid perpetuating stigma, and marketing 
content as "addiction-related." As a result, we have recommended little additional content, and rather have focused on the development of five priority areas for addiction education: etiology and public health impact; evaluation for substance use and substance use disorders; pharmacological treatment; psychosocial treatment; and overdose prevention. With any new curricular innovation, it is important to consider both trainee and program evaluation. Focusing trainee evaluation on knowledge and skill acquisition is a reasonable initial approach. The creation of standardized patient sessions or observed structured clinical examinations can be particularly attractive to course directors or trainee review committees, because these approaches allow for structured trainee feedback. Partnering with faculty who are experienced in program assessment can be particularly advantageous for program evaluation.

Other addiction-related educational efforts at our institution have focused on residency training initiatives, ${ }^{18,}{ }^{19}$ coordination of fellowship activities, ${ }^{20}$ and development of continuing educational activities at the local, regional, and national levels. As with curriculum development for medical student education, coordination and collaboration has proven to be beneficial with these teaching initiatives.

With overdose deaths reaching record numbers, the perpetuation of stigma regarding addiction as a moral failure, and inadequate training experiences at all levels of medical training, a coordinated effort to educate the next generation of providers in approaching the chronic disease of addiction is a must. We recommend that at institutions where both addiction psychiatry and addiction medicine exist, department leaders work together to foster the development of these strategic partnerships. These relationships have the potential to translate to meaningful departmental collaborations at both nearby and distant institutions, and will only promote the importance of partnering to address a nationwide epidemic. Physicians in all disciplines of medicine need to understand the impact addiction has on numerous facets of medicine and public health. We firmly believe that partnerships between psychiatry and medicine are essential in addressing the education gap with regard to addiction, and a necessary component in closing the treatment gap that so negatively contributes to the toll this deadly disease is taking on our society.

Corresponding Author: Jeanette M. Tetrault, M.D.; Department of Internal MedicineYale University School of Medicine, 367 Cedar Street, Suite 305, New Haven, CT 06510, USA (e-mail: jeanette. tetrault@yale.edu).

\section{Compliance with Ethical Standards:}

Conflict of Interest: Dr. Tetrault has no conflicts of interest to disclose. Dr. Petrakis has served as a consultant for Alkermes over the past year.

\section{REFERENCES}

1. Rudd $\mathbf{R}$, et al. Increases in drug and opioid-involved overdose deaths-United States, 2010-2015. MMWR Morb Mortal Wkly Rep. 2016;65: 1445-1452.

2. U.S. Congress. S.524 Comprehensive Addiction and Recovery Act of 2016. 2016. Available from: https://www.govtrack.us/congress/bills/ 114/s524. Accessed 6/17/17.

3. U.S. Department of Health and Human Services (HHS), Office of the Surgeon General, Facing Addiction in America: The Surgeon General's Report on Alcohol, Drugs, and Health. Washington, DC: HHS. 2016.

4. Friedmann PD, Andrews CM, Humphreys K. How ACA repeal would worsen the opioid epidemic. N Engl J Med. 2017;376(10):e16.

5. Bailey M. Medical students demand better training to tackle opioid crisis. Available at: Statnews.com. 2016. https://www.statnews.com/2016/05/ 17/opioid-addiction-medical-schools/. Accessed 6/17/17.

6. Case A, Deaton A. Rising morbidity and mortality in midlife among white non-Hispanic Americans in the 21st century. Proc Natl Acad Sci U S A. 2015;112(49):15078-83.

7. Barry CL, et al. Stigma, discrimination, treatment effectiveness, and policy: public views about drug addiction and mental illness. Psychiatr Serv. 2014;65(10): 1269-72.

8. Kreek MJ. Extreme marginalization: addiction and other mental health disorders, stigma, and imprisonment. Ann N Y Acad Sci. 2011;1231:6572 .

9. Wakeman SE. Language and addiction: choosing words wisely. Am J Public Health. 2013;103(4):e1-2.

10. van Boekel LC, et al. Stigma among health professionals towards patients with substance use disorders and its consequences for healthcare delivery: Systematic review. Drug Alcohol Depend. 2013;131(1):23-35.

11. van Boekel LC, et al. Healthcare professionals' regard towards working with patients with substance use disorders: comparison of primary care, general psychiatry and specialist addiction services. Drug Alcohol Depend. 2014;134:92-8.

12. Lipari RN, Park-Lee E, Van Horn S. America's need for and receipt of substance use treatment in 2015. The CBHSQ Report: September 29, 2016. Center for Behavioral Health Statistics and Quality Substance Abuse and Mental Health Services Administration. Rockville, MD; 2016.

13. O'Connor PG, Sokol RJ, D'Onofrio G. Addiction medicine: The birth of a new discipline. JAMA Intern Med. 2014;174(11):1717-1718.

14. O'Connor PG, Nyquist JG, McLellan AT. Integrating addiction medicine into graduate medical education in primary care: the time has come. Ann Intern Med. 2011;154(1):56-9.

15. Ayu AP, et al. Effectiveness and Organization of Addiction Medicine Training Across the Globe. Eur Addict Res. 2015;21(5):223-39.

16. Dove HW. Postgraduate education and training in addiction disorders. Defining core competencies. Psychiatr Clin North Am. 1999;22(2):481-8, xi.

17. Rasyidi E, Wilkins JN, Danovitch I. Training the next generation of providers in addiction medicine. Psychiatr Clin North Am. 2012;35(2):461-80.

18. Holt SR, et al. The Addiction Recovery Clinic: A Novel, Primary-CareBased Approach to Teaching Addiction Medicine. Acad Med. 2017;92(5):680-683.

19. Tetrault JM, et al. Developing and implementing a multispecialty graduate medical education curriculum on Screening, Brief Intervention, and Referral to Treatment (SBIRT). Subst Abus. 2012;33(2):168-81.

20. Muvvala SB, et al. An Innovative Use of Case Conference to Teach Future Educators in Addiction Psychiatry. Acad Psychiatry. 2016;40(3):494-7. 